\title{
UN ORGANE PEU CONNU \\ DE LA FORTIFICATION MÉDIÉVALE: LA GAINE
}

PAR

PIERRE HELIOT

LES murs épais de certains châteaux du Moyen Âge contiennent des couloirs longitudinaux, auxquels on a donné le nom de gaine. Il s'agit là de galeries étroites, réservées au coeur de la muraille et parallèles à l'axe de celle-ci, se développant entre deux parois maçonnées et couvertes à l'ordinaire d'une voûte en berceau. Leur destination, parfois énigmatique, a varié suivant les lieux, mais c'est en général celle d'un organe offrant un niveau de tir supplémentaire.

En Occident la gaine entra dans le répertoire des ingénieurs militaires vers la fin $\mathrm{du} \mathrm{XI}{ }^{\mathrm{e}}$ siècle au plus tard. À cette époque semble effectivement remonter le chemin de ronde, réduit à quelques tronçons aujourd'hui, qui, évidant les remparts de l'abbaye du Mont-Saint-Michel, reliait entre elles les salles du monastère. C'est un simple boyau, large de $70 \mathrm{~cm}$. seulement et prenant jour sur le dehors à travers des meurtrières. ${ }^{1}$ On trouve une disposition analogue au donjon de Loches, contemporain de l'enceinte précédente ou érigé seulement vers $1100 .^{2}$ Ici deux couloirs armés de petites archères s'embranchent sur la grande salle du second étage: l'un, encastré dans le mur sud-est de la grosse tour et de l'avantcorps, se prolonge par un escalier droit conduisant à l'étage supérieur, tandis que l'autre, logé dans les murs nord-est et nord-ouest, descend en rampe douce vers l'étage inférieur. Chacune de ces galeries remplissait une double mission: celle d'une voie de circulation et celle d'un organe défensif, car leurs maigres ajours permettaient à des tireurs de battre les abords de l'ouvrage. Des couloirs s'engageaient aussi dans l'enveloppe du donjon d'Arques, bâti en Haute-Normandie vers 1120-1130. Plusieurs reliaient entre eux les étages et les salles, mais deux autres, coudés en équerre à l'un des angles de l'édifice, avaient pour objet de défendre l'escalier d'accès, construit hors oeuvre et en contrebas. ${ }^{3}$

1 Ch.-H. Besnard: Le Mont-St-Michel, Paris 1911, pp. 64-65; P. Gout: Le MontSt-Michel, Paris 1910, t. II, fig. p. 433.

2 J. Vallery-Radot: Loches, Paris 1926, p. 31 suiv., et Loches, dans le Congrès archéol. de France, t. CVI, 1948, p. 117.

${ }^{3}$ S. Toy: A bistory of fortification from 3000 B.C. to A.D. 1700, Londres 1955, pp. 80-81; E. Viollet-LE-Duc: Dictionnaire raisonné de l'architecture française..., Paris $1861-1868$, t. V, p. 38 suiv. La reconstitution de l'édifice par ce dernier auteur appelle bien des corrections. 
La formule fit son chemin çà et là. Au reste les murs épais des châteaux romans et gothiques - ceux des donjons plus souvent que ceux des tours et des courtines - s'évidaient couramment pour héberger des escaliers, de brefs couloirs et des pièces exiguës: chambrettes, latrines et réduits divers. La gaine offrait un niveau de tir supplémentaire, doublant

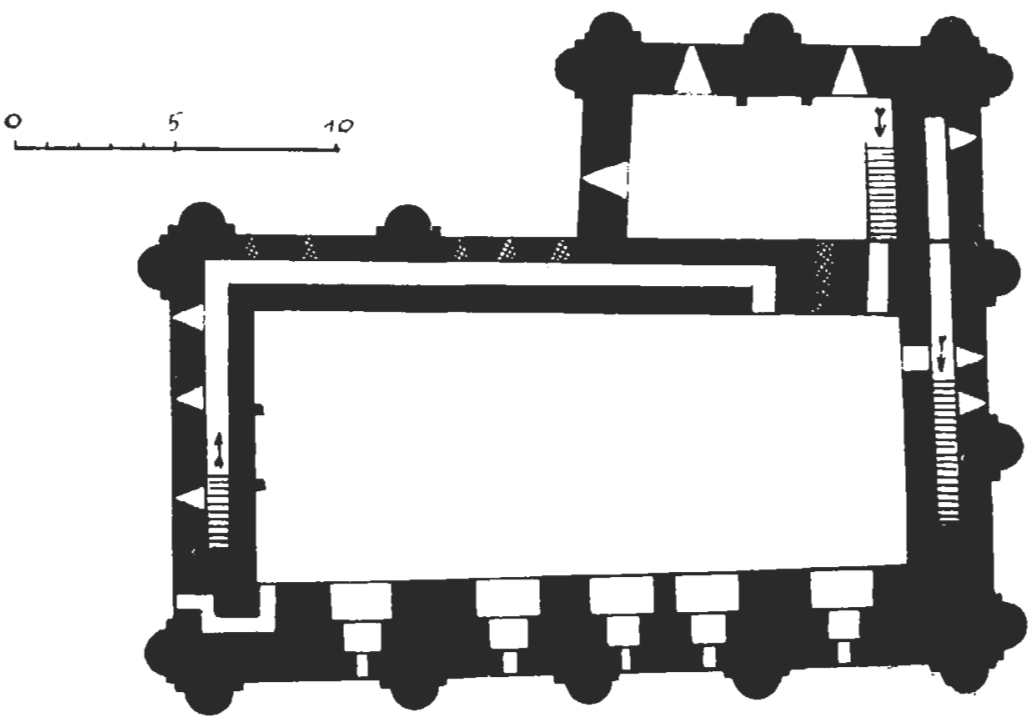

Fig. 1.-Loches. Donion, plan du $2^{c}$ élage, par P. Héliol.

ou triplant celui que constituait déjà le chemin de ronde et ménagé, tantôt au pied des murailles, tantôt à mi-hauteur environ, tantôt presque à leur sommet. Telles sont les gaines du front méridional des remparts à Villefranche-de-Conflent en Roussillon, oeuvre du XII ${ }^{c}$ siècle; ${ }^{4}$ de

+ Voir les études de Mlle, A. DE Pous: L'arcbitecture militaire occitane (IX"-XIV" siècles), dans le "Bull, archéol du Comité des travaux hist.», nouv. série, t, V, 1969. p. 74; La cilé de marbre: Villefranche, capilale du pays de Confíenl, Paris 1966, phot, de la couverture et fig. 3; Villefranche-de-Conflent, dans le Congrès arcbéol. de France, t. CXII, 1954, p. 286. La date de construction de la gaine est incertaine. Elle est comprise 'entre celle' de la fondation de la ville (vers 1090) et les dernières années du XIII siècle, car on interrompit le couloir lorsqu'on prolongea les collatéraux de l'église vers 1260-1294. La gaine Iongeait le front méridional de l'église, dont les parties les plus anciennes ne remontent pas au delà du milieu du XII' siècle; une porte l'unissait jadis au collatéral sud, ajouté à la fin du même siècle. Les meurtrières qui l'ajourent sont tellement nombreuses que je dois attribuer la très grande majorité d'entre elles à une époque postérieure au Moyen Âge. 
l'enceinte du château de Termes dans les Corbières, renouvelée sans doute au début du XIII $I^{\mathrm{e}}$, peu avant ou plus probablemer.t peu après $1210 ;^{5}$ du front sud-ouest des murailles du château de Chalucet en Haut-Limousin

FIG. 2.-Chalucet. Cháleau, cnirće acluelle de la gaine. (Coll. H.P. Eydoux).

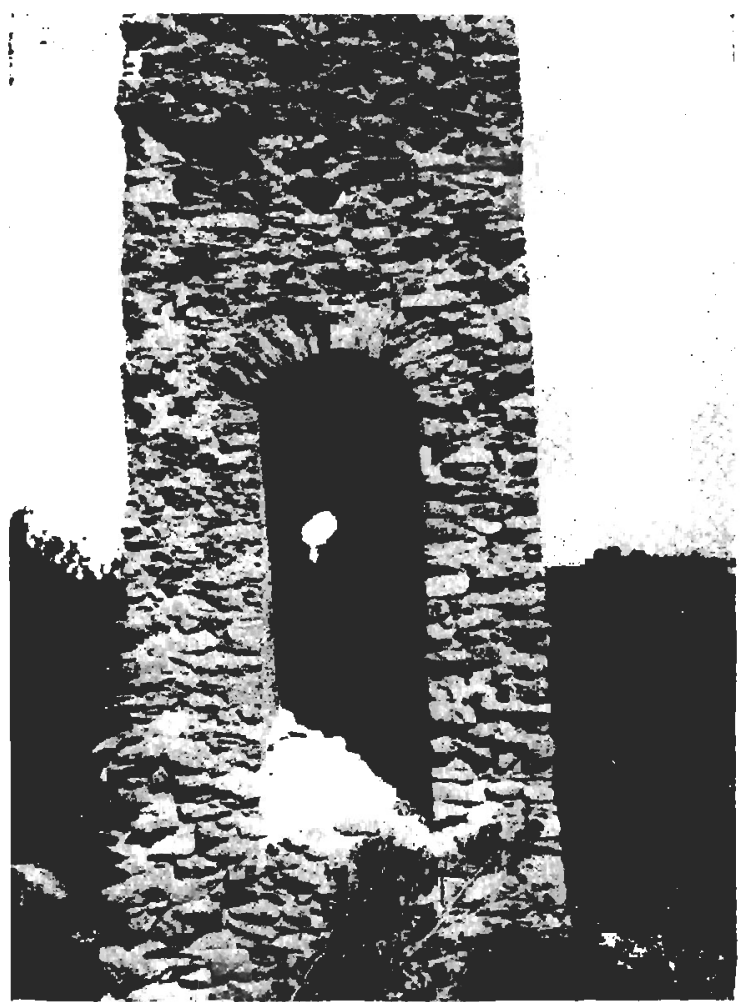

où, datant sans doute du XIII siècle, elle mesure $1,20 \mathrm{~m}$. de large et plus de 2,50 m. de haut; ${ }^{6}$ de l'enceinte du château de Benauges en Borde-

5 A. DE Pous: Le Perapertusés (Aude) et ses châteaux, dans le «Bull. monumental», t. XCVIII, 1939, p. 32. Sur l'age de cette enceinte, A. DE Pous: L'archit. occilane, op. cit., pp. 93-94, et P. HÉLIoT: L'áge du cbäteaul de Carcassonne, dans les «Annales du Midi», t. LXXVIII, 1966, p. 17.

${ }^{6}$ H.-P. Eypoux: Cháteaux fantastiques, Paris 1969-1971, t. I, p. 152; L. GulBerT: Chálucet, dans le «Bull. de la Soc, archéol, et hist. du Limousin», t. XXXIII, 1886, p. 121, plan et pl. en face de la p. 144; F. de Verneilh: Rapport..., dans le «Congrès archéol, de France», t XIV, 1847, pp. 418 et 421; A. Demartial: Chal»cet, ibid., t. LXXXIV, 1921, p. 266. 
lais, bâtie dans la seconde moitié de ce siècle ${ }^{7}$ de celle du château de la Réole en Bazadais, construite vraisemblablement peu après $1254 ;^{8}$ des remparts du château bas-normand de Domfront où, large d'un mètre et haute à peu près du double, élargie aussi par places devant les embrasures de tir, elle ne saurait remonter au delà du XIII ${ }^{\mathrm{e}}$ siècle ${ }^{9}$ enfin de l'enceinte intérieure du château de Beaumaris, érigée entre 1294 et 1300 dans l'ile d'Anglesey. ${ }^{10}$ D'autres gaines voûtées et armées d'archères furent ménagées au XIII ${ }^{c}$ siècle à l'intérieur de deux des courtines du château gallois de Manorbier au comté de Pembroke, au niveau du premier étage des bâtiments adjacents. ${ }^{11}$ Eclairées par de très petites fenêtres et par des jours de souffrance, celles du front sud du château de Najac en Rouergue, construites vers $1255-1260$, reliaient le donjon gothique au donjon roman, en passant à travers une tour intermédiaire; couvertes d'un berceau en pierre sur toute leur longueur, elles abritaient deux tronçons de couloir placés à des niveaux différents et que raccordait un escalier droit. $^{12}$

Plusieurs gaines méritent de nous arrêter quelque peu. Il y a des couloirs muraux dans les églises romanes de la France méridionale, parfois vouées à une destination essentiellement, voire purement défensive. ${ }^{13}$ Tel est le cas des chemins de ronde périphériques, adossés aux reins de coupoles et dotés de petites fenêtres susceptibles de servir de meurtrières à l'occasion. J'en puis citer deux. Le plus ancien, remontant au second quart du XII ${ }^{e}$ siècle ou environ, large de $75 \mathrm{~cm}$. et haut de $1,75 \mathrm{~m}$. en chiffres ronds, se poursuit autour de l'abbatiale de Souillac en Quercy; des baies percées dans la calotte des coupoles y permettaient même de

' J. Gardelles: Les châteaux du Moyen Âge dans la France du S.-O.: La Gascogne anglaise de 1216 à 1327, Genève-Paris 1972, p. 97.

8 Ibid, p. 156 .

${ }^{9}$ L. Blanchetrère: Le donjon ou château féodal de Domfront, $2^{e}$ éd., Domfront 1892, p. 59 suiv.; A. H. THOMpson: Military architecture in England during the Middle Ages, Oxford 1912, pp. 284-285.

${ }^{10}$ Royal Commission on ancient and bistorical monum. in Wales: an inventory of the ancient monum. in Anglesey, Londres 1937, p. 11. Sur la date, H. M. Colvin, R. A. BROWN et A. J. TAYLOR: The bistory of the King's works, t. I, Londres 1963, p. 308 suiv.

" D. J. C. King et J. C. Perks: Manorbier castle, dans l'«Archaeologia Cambrensis», 1970, pp. 102 et 110 .

${ }_{12}$ H. NodE'T: Le château de Najac en Rouergue, dans le «Bull. monumental», t. LIII, 1887, p. 150; Fr. SALET: Najac: château, dans le "Congrès archéol. de France», t. C, 1937, pp. 188, 190 et 196; Eydoux, op. cit, t. III, p. 80.

is P. HÉliot: La cathédrale de Cefalu... et les galeries murales dans les églises romanes $d u$ Midi, dans l'«Arte lombarda», t. XI, 1966, p. 7, et Les coursières et les passages muraux dans les églises du Midi de la France, de l'Espagne et du Portugal aux XII" et XIV" siècles, dans l'«Anuario de estudios medievales», I. VI, 1969, pp. $188-190$. 
tirer sur des ennemis qui eussent pénétré dans la nef. ${ }^{14}$ CEuvre aussi du $X I I^{*}$ siècle, la souche du clocher central d'Agonac en Périgord contient deux couloirs, à peine moins hauts et larges que le précédent, mais occupant deux niveaux différents et couverts de plafonds dallés: l'un établi au revers des murs nord et est, l'autre longeant le flanc sud. ${ }^{15}$ L'ensemble le plus développé nous est fourni par l'ex-abbatiale, puis cathédrale de Saint-Pons-de-Thomières en Bas-Languedoc, élevée probablement vers 1160-1180. C'était un monument à nef unique, coiffée d'un berceau en pierre et contournée par deux chemins de ronde également voûtés: celui du bas s'ouvrant sur le vaisseau par des fenêtres exiguës et sur le dehors à travers des archères; le second exposé d'abord à l'air libre, puis voûté à son tour, peut-être au XIII ${ }^{\mathrm{e}}$ siècle. ${ }^{16}$

Erigé vers 1170-1190, cylindrique à la différence de ceux de Loches et d'Arques qui sont cubiques, le donjon de Châteaudun nous offre des dispositions analogues. Les deux salles inférieures en sont couvertes de coupoles, que contournent deux couloirs annulaires, armés de meurtrières. Ces galeries fournissaient évidemment deux niveaux de tir superposés comme à Saint-Pons; la destination de celle du dessus est encore affirmée par les bancs de pierre installés en face des embrasures. ${ }^{17}$ L'idée d'aménager des couloirs périphériques, non pas au coeur des murs d'enveloppe selon l'usage habituel, mais dans l'épaisseur des maçonneries de remplissage qui épaulent ou ceinturent un berceau ou une coupole, me paraît avoir été importée du Midi où nous venons d'en voir quelques exemplaires plus âgés ou contemporains à Souillac, Agonac et Saint-Pons. Vers 11901200 on réédita la formule sur une autre forteresse de la maison de BloisChampagne: le donjon prismatique de Châtillon-Coligny en Gâtinais, mais en réduisant le nombre des couloirs à un seul. ${ }^{18}$

14 J. SECRET: A propos de chambres ménagées dans les grands arcs d'une coupole, dans le «Bull, monumental», t. CXXV, 1967, p. 163; M. Vidal, J. Maury et J. PorCIIER: Qucrcy roman, la Pierre-qui-vire 1959, p. 287; R. REY: La catbédrale de Cabors et les origines de l'archit. à coupoles d'Aquitaine, Paris 1925, figs. 74 et 77.

is J. Secret, op. cit., pp. 62-63; chan. Roux: Agonac, dans le "Congrès archéol. de France», t. XC, 1927, p. 201 suiv.

${ }_{16}$ M. Durliat: St-Pons-de-Thomières, dans le «Congrès», cit., t. CVIII, 1950, p. 272 suiv.; M. DE Dannville: Les églises romanes du diocèse de Montpellier, dans le «Monspeliensia», t. II, 1935-1940, p. 188; J. SAHUC: L'art roman à St-Pons-deThomières, Montpellier 1908, pp. 21, 26, 27 et 44.

${ }_{17}$ P. Héliot: La grosse tour de Cháteaudun et les donjons du XII siècle, dans le «Bull. de la Soc, nat. des antiquaires de France», 1968, pp. 228-229; Dr. FR. LEsueur: Châteaudun: château, dans le «Congrès», cit., t. XCIII, 1930, p. 480 suiv.

${ }^{\prime} \mathrm{H}$. DE Curzon: Le donjon de Châtillon-s/Loing, dans les "Annales de la Soc. hist. et archéol. du Gâtinais», t. XV, 1897, pp. 139-141 (les proportions données au donjon dans la coupe transversale qui illustre cet article sont certainement erronées, de même que les plans); Hélrot, op. cit., pp. 238-239. 


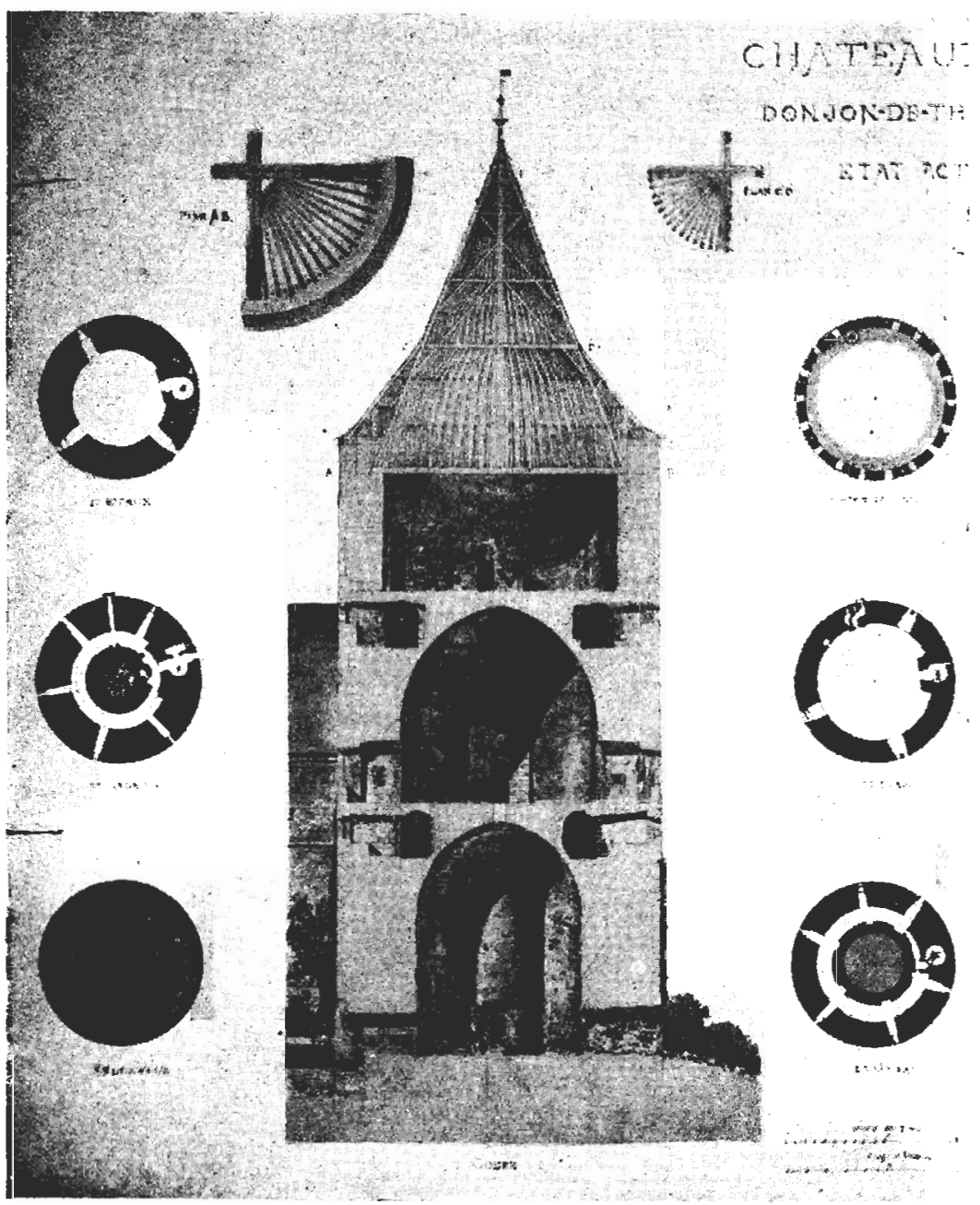

FIG. 3.-Châteaudun. Donjon, coupe el plans aux différents niveaux, par Barlèt. (Coll. Arch. phot.).

$\Lambda$ la fin du siècle, probablement vers $1185-1190$, on la reprit au bénéfice de la tour d'Avranches, puissant ouvrage polygonal, planté à un angle fort exposé de l'enceinte extérieure au château de Douvres. Ici deux gaines superposées, également voûtées en berceau, desservent deux étages 
d'archères. ${ }^{19}$ Il en existe des diminutifs contemporains à la Bell Tower de la Tour de Londres. ${ }^{20}$

En faisant bâtir aux environs de Niort leur château du CoudraySalbart entre 1202 et 1242, probablement après $1226,{ }^{21}$ les sires de

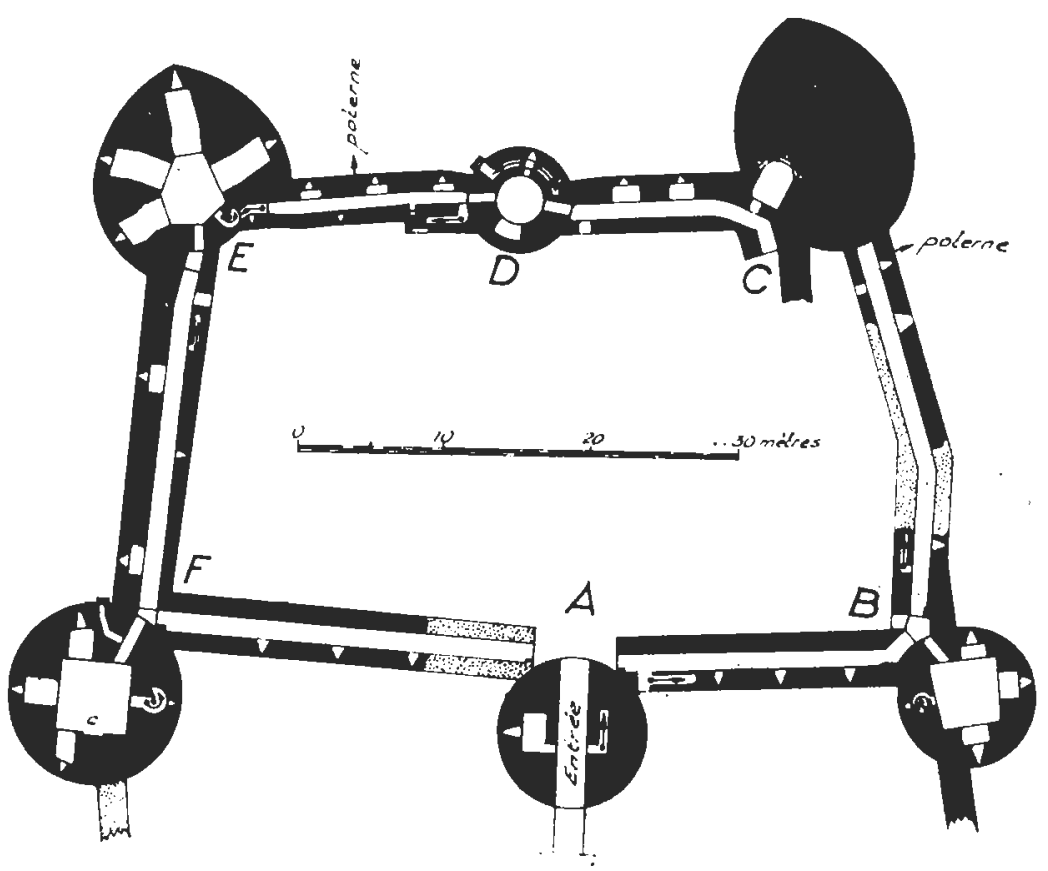

Fig. 4.-Le Coudray-Salbart. Cbâteau, plan du rez-de-chaussée, par E. Aurriault.

Parthenay firent aménager à la base des courtines une gaine qui accomplirait le circuit complet du corps de place, si les tours ne l'interrompaient

19 D. F. Renn: The Avranches traverse at Dover castle, dans l'«Archaeologia Can(iana». t. LXXXIV, 1969, pp. 79-89.

${ }^{20}$ Royal Commission on bistorical monum. (England): an inventory of the bist. monum. in London, t. V, Londres 1930, p. 80. Sur la date, Colvin-Brown-TAYlor, op. cit., t. I, p. 708 suiv. Les couloirs en question sont brefs et ne contournent pas l'ouvrage. Construit vers 1180 pour le comte de Surrey, le donjon de Conisbrough dans l'Yorkshire paraît avoir été couronné de deux chemins de ronde superposés: celui du dessous couvert et celui du sommet à l'air libre; cf. S. Toy: The castles of Great Britain, $2^{c}$ éd., Londres 1954, pp. 106-107.

${ }_{21}$ P. HÉliot: Les donjons de Niort et la fortification médiévale, dans la «Rev. du Bas-Poitou et des provinces de l'Ouest», 1970, pp. 68-69. 


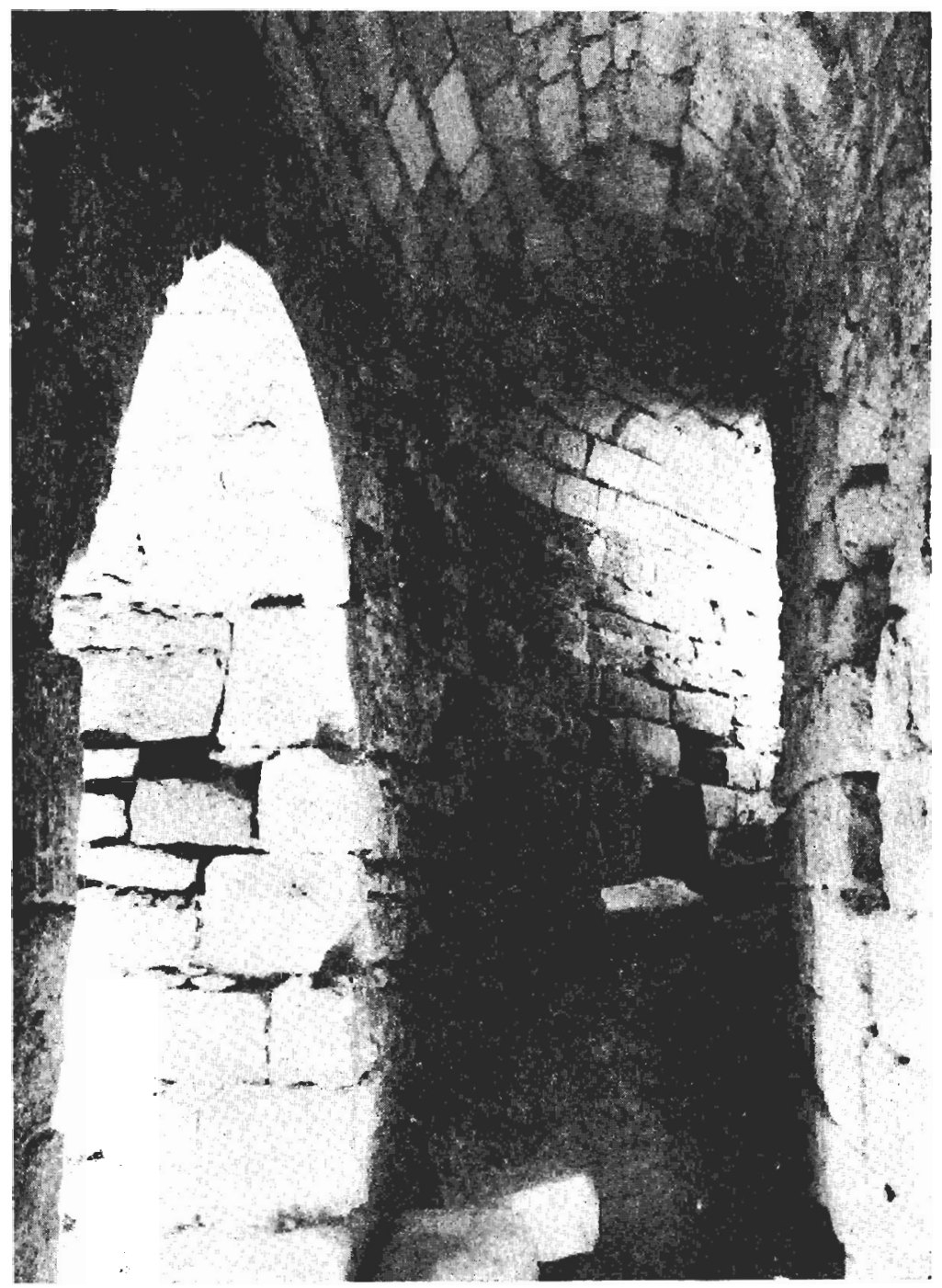

FIG. 5.-Le Coudray-Salbart. Château, gaine des remparts. (Coll. H.-P. Eydoux).

par endroits. Voûtée en berceau comme d'habitude, large d'un mètre à $1,30 \mathrm{~m}$., haute de trois en moyenne, cette galerie est éclairée par des 
meurtrières qui regardent pour la plupart le dehors, mais dont quelques unes s'ouvrent sur la cour, ${ }^{22}$ tandis que plusieurs assommoirs sont percés dans les voûtes. ${ }^{23}$

La manufacture de glaces de Saint-Gobain dans le Laonnois occupe depuis près de trois-cents ans l'emplacement d'un château, que les sires de Coucy paraissent avoir bâti dans la première moitié du XIII ${ }^{e}$ siècle et

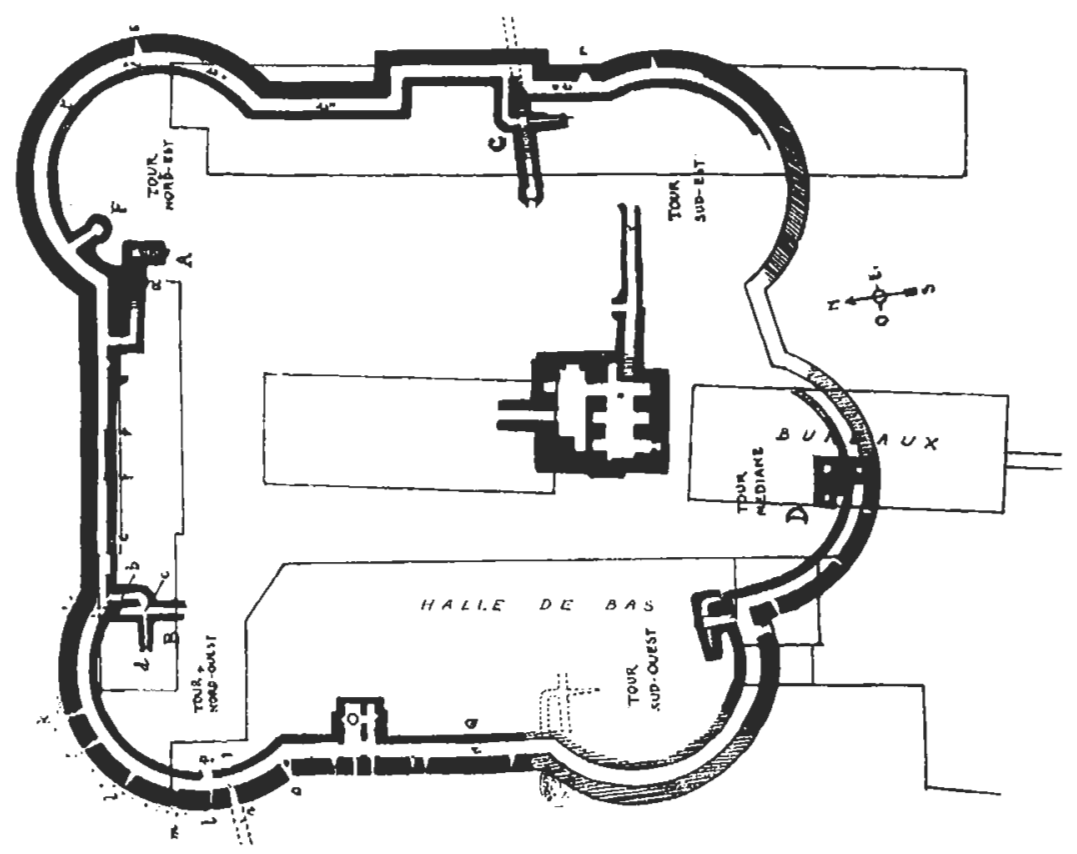

FrG. 6.-Saint-Gobain. Plan des galeries souterraines et des caves du château, d'après I. Peychès.

dont il ne reste plus que les substructions. En explorant les souterrains de la forteresse on a reconnu, sur les trois quarts de son circuit, une gaine qui accomplissait le tour complet de l'enceinte extérieure et de ses

${ }^{22}$ Elle fut qualifiée de "contremines faites à archères et canonnières» dans un inventaire de 1460 .

${ }^{23}$ Eydoux, op. cit., t. II, pp. 54.58, et Le château du Coudray-Salbart, dans le «Bull. monumental», t. CXXV, 1967, pp. 250 et 256; 1'-col. E. Espérandieu: Le chateau du Coudray-Salbart, dans les Paysages et monum, du Poitou, t. VI, fasc. I, Paris 1892, p. 29 suiv. 
bastions. C'est une galerie large de 2,20 m. en général, voûtée en berceau et dotée de nombreuses archères. Elle desservait au passage quelques salles creusées dans le sol et quelques escaliers descendant à des poternes qui s'ouvraient au fond du fossé. ${ }^{24}$ À ma connaissance aucune en France n'atteint un pareil développement.

La tour Constance d'Aigues-Mortes a vu le jour vers 1249 . C'est un ouvrage cylindrique, contenant deux salles voûtées, dont la première est enveloppée, au niveau des retombées d'ogives, par un couloir annulaire qui dessert à la fois les latrines et les chambres de manoeuvre des herses

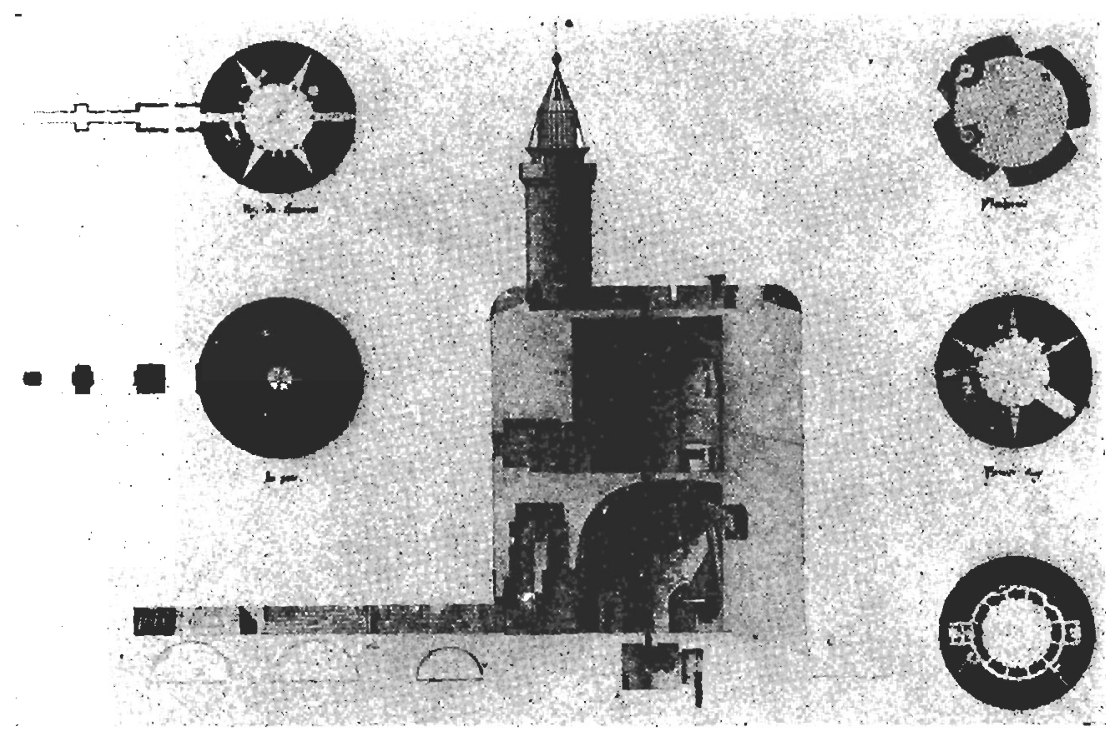

Fig. T.-Aigues-Morles. Tour Conslance, coupe el plans aux différents étages, par Louzier. (Coll. Arch. phot.).

barrant jadis les entrées de l'ouvrage. C'est en outre là que débouche l'orifice du puits. Large de $80 \mathrm{~cm}$., le couloir représente peut-être une version modernisée de ceux de Châteaudun, au moins de celui du bas,

${ }^{24}$ I. Pexchès: Noles sur le château-forl de St-Gobain, Dijon 1945, p. 21 suiv.; P. Hélıo't Le châleau de St-Gobain el les châteaux golbiques de plan concentrique '"n Europe occidenlale, dans le «Bull. de la Soc. nat. des antiquaires de France», 1973. 


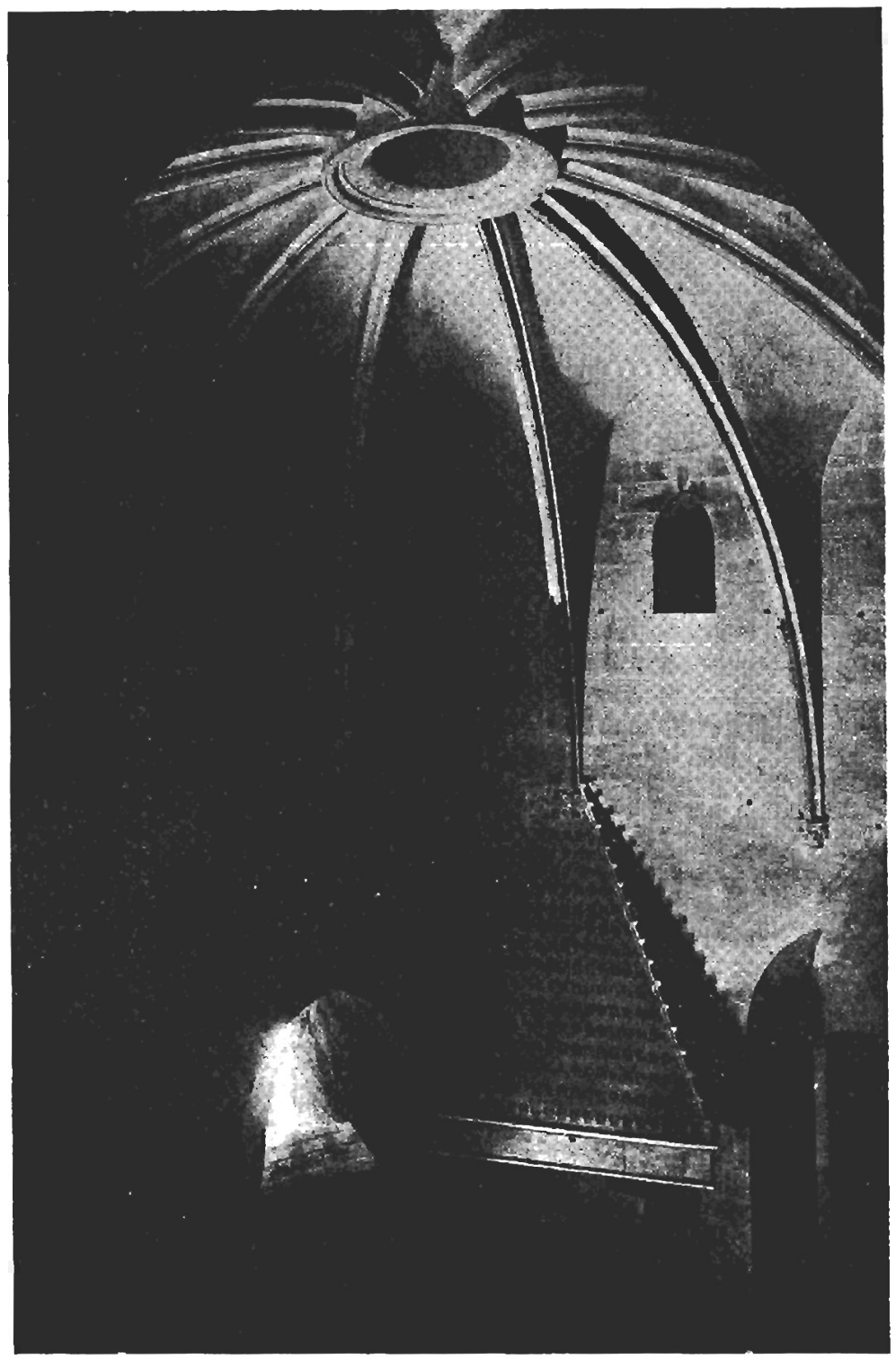

Fig. 8.-Aigues-Morles. Tour Conslance, salle basse. (Coll. Arch, phot.). 
situé au même endroit, ${ }^{25}$ mais il en diffère par son insertion au coeur du mur au lieu des maçonneries de remplissage, par la réduction du nombre des meurtrières à une seule et par les petites fenêtres ouvertes sur la salle basse. Il s'agit donc d'une galerie de service plus que d'un chemin de ronde. On a supposé qu'en cas d'attaque on le garnissait d'archers qui eussent accablé de leurs traits un ennemi ayant réussi à forcer la porte. C'est possible, quoique la salle et davantage encore le couloir fussent bien sombres pour se prêter aisément à une telle tactique. ${ }^{26}$

Le grand ingénieur militaire Jacques de Saint-Georges, passé du service des comtes de Savoie à celui d'Edouard $I^{\text {er }}$ d'Angleterre en $1278,{ }^{27}$ ne négligea pas toujours d'introduire la gaine dans son répertoire, au

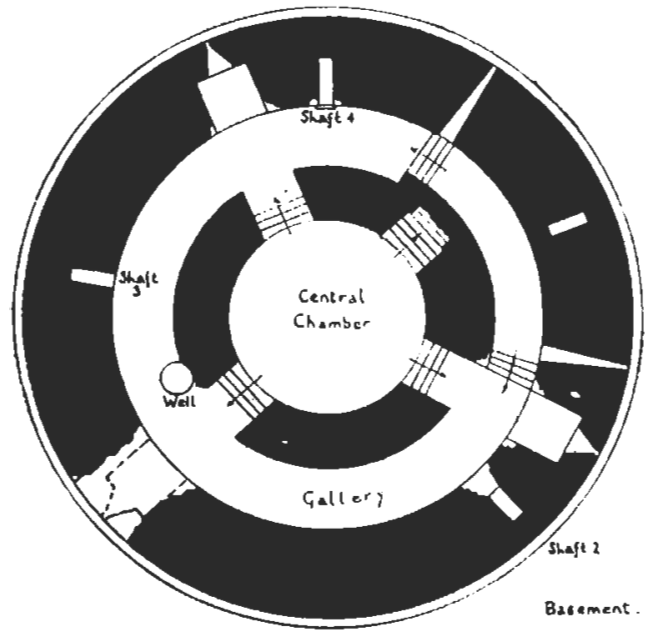

FIG, 9.-Flint. Donion, plan de l'élage intérieur, par $D$. King.

moins en faveur des châteaux de Flint, Caernarvon et Beaumaris, tous situés dans l'extrême Nord du pays de Galles et construits probablement sous sa direction. Laissons de côté le dernier, déjà cité, mais examinons les deux autres que recommandent certains traits particuliers. A Flint,

${ }^{25}$ A Châteaudun le vestibule d'entrée et le puits débouchent l'un et l'autre dans le chemin de ronde inférieur.

${ }^{26}$ C. B. Bothamley: The walled town of Aigues-Mortes, dans «The archaeological journ.m, t. LXXIII, 1916, pp. 226-230 et 231; A. FliCHE: Aigues-Mortes et St-Gilles, Paris 1925, p. 18, et Aigues-Mortes, dans le «Congrès archéol. de France», t. CVIII, 1950, pp. 92-93; L.-H. LABANDE: Guide archéol. du congrès, ibid., t. LXXVI, 1909, fasc. I, p. 186 suiv.

${ }^{27}$ Sur le personnage voir en dernier lieu Colvin-Brown-TAYLOR: Hist. of the King's works, op. cit., t. I, pp. 203-205. 
érigé entre 1277 et $1284,{ }^{28}$ le donjon nous retiendra seul. C'est une forte tour cylindrique, largement décapitée. L'étage inférieur comporte une salle basse, reliée par trois arcades à un couloir annulaire, armé de quelques archères et passant sous l'étroit vestibule d'entrée. Des soldats postés dans cette galerie auraient pu contre-attaquer un adversaire faisant irruption par la porte, si l'éclairage le leur avait permis. ${ }^{29}$ On a comparé cette disposition à celle d'Aigues-Mortes, non sans raison, quoique la filiation de la plus jeune par son aînée soit des plus incertaines. Caernarvon fut commencé l'an 1283. On y travaillait encore au début du XIV siècle, mais on en acheva peut-être les fronts sud et est, que la ville emmuraillée ne protégeait point, avant 1293 . On a réservé au coeur des courtines de ces deux fronts une galerie couverte de dalles, armée de meurtrières et contournant même les salles de plusieurs tours. ${ }^{30}$

Par exception l'enceinte du château de Gisors, qui remonte au XII siècle, nous montre une variante de la gaine, car on la doubla sur sa face occidentale au moyen d'une galerie hors oeuvre, qui paraît s'être prolongée jadis sur le front nord-ouest. Le tronçon subsistant de cet ouvrage extérieur, bâti à un mètre en avant du pied de la courtine, s'aligne sur les tours. Matelassé et dissimulé par un remblai de terre qui formait terrasse pour l'artillerie, primitivement accessible par des portes percées dans les joues des tours, le couloir est large de deux mètres environ et couvert d'un berceau en maçonnerie. ${ }^{3 t}$ Son âge prête à controverses. $M$. Pépin propose le XIV $V^{e}$ siècle, tandis que $M$. Bruant opte pour le XVI ${ }^{e}$. Remarquons d'abord que les meurtrières sont des fentes se prêtant mal aux armes à feu, ce qui nous interdit d'en faire descendre la date au delà de 1450-1460. En outre la galerie et le remblai, se complétant mutuellement, répondaient assurément au même programme et résultèrent sans doute d'une seule campagne de travaux. L'idée de renforcer la capacité de résistance des murailles par l'addition d'un épais matelas en terre vint aux ingénieurs militaires dès le début du $X V^{*}$ siècle, donc bien avant d'entrer dans la pratique courante après 1500 . En voici deux preuves. L'an 1415 ou 1416 l'on «emplit» de terre la barbacane de la porte des Dunes à Boulogne-sur-Mer. ${ }^{32}$ En 1477 le Magistrat d'Arras fit «enterrer»

${ }^{24}$ Ibid., t. I, p. 308 suiv.

${ }^{29}$ D. J. C. KING: The donion of Flint, dans le «Chester archacological soc, journ.», t. XLV, 1958 , p. 61 suiv.; ToY, op. cit., p. 167.

${ }^{30}$ Royal Commission on ancient and bist. monum, in Wales: an inventory of the ancient monum. in Caernarvonshire, t. II, Londres 1960, pp. 127 et 131 suiv.; A. J. TAYloR: Caernarvon castie and town walls, Londres 1964, pp. 21 et 27-32. "Y. BRUAND: Le château de Gisors: principales campagnes de construction, dans le «Bull. monumental», t. CXVI, 1958, pp. 262-264; E. PÉPIN: Gisors et la vallée de l'Epte, Paris 1939, pp. 46, 48 et 49, et $2^{\mathrm{e}}$ éd., Paris 1963, pp. 31-32.

${ }_{32}$ Registre des recettes et dépenses de la ville de Boulogne (1415-1416), 
la porte Méaulens. ${ }^{33}$ J'en conclus qu'à Gisors le remblai et la galerie remontent à la seconde phase de la guerre de Cent Ans, c'est-à-dire aux années comprises entre 1415 et 1450 , probablement à la double décennie de la reconquête: 1430-1450. Si mon hypothèse cst juste, ils furent l'oeuvre des Anglais.

À cette époque les gaines répondaient à plusieurs usages, comme nous allons le constater. Reconstruits au XVI ${ }^{\mathrm{c}}$ siècle, les nefs et bascôtés de l'église de Toucy en Auxerrois sont limités au nord et à l'ouest par deux branches des courtines de l'ancien château. En conséquence leur façade est constituée par un tronçon de rempart, unissant une grosse tour d'angle à une forte tourelle d'escalier, qui ne me paraissent pas antérieures au $\mathrm{XIII}^{\mathrm{c}}$ siècle. Entre les XIII ${ }^{\mathrm{c}}$ et $\mathrm{XVI}{ }^{\mathrm{e}}$ - je ne saurais préciser- on a relié ces deux ouvrages par deux couloirs superposés: simples voies de communication totalement incluses dans la maçonnerie. ${ }^{\downarrow}$ On a découvert quelques gaines dans le château de Ham en Vermandois: l'une, logée dans la courtine du front nord, remontait peut-être au XIII" siècle alors quc les deux autres, établies à deux niveaux différents de la courtine sud, ne dataient sans doute que du $X V^{c}$ car la brique s'associait à la pierre dans leur construction. ${ }^{35}$ La première et l'une des deux autres étaient-elles des galeries de contremine, à l'image de celle dont on gratifia la chemise du donjon de Coucy vers 1386 ? $^{\text {t6 }}$ Au défunt château de Dijon, édifié de 1477 à 1512, deux galeries superposées évidaient la masse des remparts sur les quatre faces du monument; celle du dessous, seulement plafonnée, servait à l'écoute, mais la seconde, voûtée, donnait accès à des embrasures à canon, de même que le couloir contournant à sa base le boulevard Louis XII ajouté entre 1498 et $1512 .^{37}$ Les Espagnols accueillirent la gaine çà et là. En renouvelant au dernier quart du XVc siècle, probablement vers 1479-1480, le château de la Mota dans la province de Valladolid, près de Medina del Campo, le constructeur assit le corps de place sur une plateforme qu'enserre un épais rempart, flanqué de tours, selon le parti adopté deux siècles auparavant à Saint-Gobain. Les courtines de

ćd. L. Dupont, dans les «Mém. de la Soc. académique de Boulogne», t. VII, 1882, pp. 206 et 250.

33 Jean Molinet: Chroniques, éd. G. Doutrepont et O. Jodogne, Bruxclles 1935-1937, t. I, p. 189.

${ }_{34}$ P. BARBIER: Les châtealtx et les églises de Toucy..., Auxerre 1940, pp. 82, 83, 96 et 97, et La France féodale, St-Brieuc 1968, t. I, p. 468 suiv.

3. A. Mersier: Le château de Hem, dans le «Bull. monumental», t. LXXVIII, 1914 , pp. 258 et 315. p. 82 .

"E. Lefievre-Pontalis et Ph. Lauer: Le château de Coucy, 2 éd., Paris 1928,

"2 Crr. Sursse: Architecture militaire bourguignonnc: restauration du château de Dijoit, Paris 1876, pp. 30,50 et $55, \mathrm{pl}, 1,5,8$ et \%. 
l'enceinte extérieure sont évidées par deux couloirs superposés et voûtés, reliés entre eux par des escaliers et dotés de meurtrières: celui du dessus ayant pour unique objet de fournir un niveau de tir supplémentaire; le second répondant au même but, tout en remplissant assurément en outre l'office de galerie de contremine. ${ }^{38}$ Enfin, en bâtissant le fort de Salses en Roussillon vers l'année 1500, l'ingénieur Ramírez ménagea à la base de l'escarpe de l'ouvrage un couloir périphérique voûté, dont nous ne savons au juste s'il fut destiné primitivement au tir ou à l'écoute, et dota les demi-lunes de galeries de contremine. ${ }^{39}$

Faut-il assimiler aux gaines les galeries murales périphériques qui s'ouvrent à travers des arcades sur des salles d'habitation ou d'apparat, au sommet de quelques grands donjons-palais cubiques d'Angleterre, construits au cours d'une période couvrant la fin du XI $\mathrm{XI}^{c}$ siècle et la quasi-totalité du suivant? On établit ces passages, tantôt à un niveau supérieur au plancher de la salle comme à la Tour Blanche de Londres, prototype apparent de toute la série, tantôt de plain-pied avec le plancher, suivant que la pièce était éclairée par deux étages de fenêtres ou par un seul. En dehors de Londres, le premier groupe est représenté à Rochester, à Hedingham dans l'Essex et à Douvres; le second à Norwich et à Rising en Norfolk. ${ }^{40}$ Chemins de ronde propices au tir? Je le veux bien, encore que les fenêtres fussent larges. Tribunes à l'usage des spectateurs des fềtes? C'est encore possible, mais la filiation ne me semble guère douteuse. A mon sens il ne faut pas la chercher en des organes de fortification, mais en ces coursières intérieures qui, dans le royaume anglo-normand, passaient le long des fenêtres hautes des grandes basiliques romanes, detrière un rideau d'arcades. L'identité de structure appuie mon hypothèse. D'ailleurs la grande salle du palais royal de Westminster, lequel n'était nullement fortifié, offrait une réédition exacte de ces passages à claire-voie des cathédrales et des abbatiales, postérieure de quelques années seulement à celle de la fameuse Tour.

Ces ordonnances firent-elles écho sur le continent? Dans le feu donjon cylindrique du palais royal de Laon, érigé sur l'ordre de Philippe

3. A. Fernández Casanova: El castillo de la Mota, dans le "Boletín de la Soc. española de excursiones», t. XII, 1904, p. 10, pl. 2-3; Y. BRUAnd: De l'importance bist. et de la valeur militaire des ouvrages fortifiés en Vieille-Castille au $X V^{*}$ s., dans «Le Moyen Âge», 1957, pp. 79-80; F. ChueCA Gorrin: Historia de la arquitectura española: Edad Antigua y Edad Media, Madrid 1965, pp. 535-536.

${ }^{39}$ S. STYM-Popper: Le château de Salses, dans le "Congtès archeol, de France", t. CXII, 1954, pp, 417,418 et 422.

to P. Héliot: L'évolution du donjon dans le N.O. de la France et en Angleterre au XII" s., dans le "Bull. archéol. du Comité des travaux hist.», nouv. série, t. V, 1969, pp. 149, 150, 154 et 177. 
Auguste entre 1204 et $1212,{ }^{41}$ un étroit couloir, logé au coeur de la muraille, contournait la salle du premier étage à mi-hauteur et s'ouvrait sur cette dernière à travers de larges baies, percées entre les retombées de la voûte d'ogives. ${ }^{42}$ La salle ne se prêtant nullement à des fêtes, je doute fort à la réflexion qu'il s'agisse d'une réplique des tribunes britanniques. Au reste le souverain résidait dans un autre bâtiment. Assimilerons-nous la gaine à un chemin de ronde pourvu d'archères et devonsnous y voir une version modernisée de celles de Châteaudun? Nous ne savons même pas si des meurtrières l'accompagnaient. Faut-il la considérer comme une préfigure de celle de Coucy, toute voisine et que je vais examiner? L'hypothèse semble juste. En tous cas une comparaison avec la tour Constance est inutile puisque, la porte étant placée au rez-dechaussée, le couloir de Laon passait bien au dessus de la chambre de la herse au lieu de la desservir.

Le donjon de Coucy est heureusement mieux connu, car les archéolo. gues l'ont analysé méthodiquement avant que les Allemands le fissent sauter. Bâti vers 1230-1240, apparemment d'après le modèle du précédent, mais sur une échelle considérablement amplifiée, il se divisait en trois salles superposées, dont un large oeil central perçait chacune des voûtes comme à Laon. Ce dispositif permettait de hisser jusqu'à la plateforme terminale les approvisionnements, les munitions, les armes et le matériel entreposés dans les salles basses. Un couloir circulaire, éclairé par deux fenêtres, mais démuni de meurtrières contournait la salle haute à mi-hauteur et s'ouvrait largement sur elle. Les arcades bandées entre les retombées des ogives de la voûte lui donnaient des allures de tribunes, ce qu'accentuaient des balcons en bois dont on a reconnu des vestiges. Il est probable que tout cela servait d'arsenal. ${ }^{43}$

Reste à savoir si les ingénieurs militaires de l'Occident inventèrent la gaine au $\mathrm{XI}^{\mathbf{e}}$ siècle ou s'ils l'empruntèrent à des étrangers qui les auraient devancés. Les Normands avaient bien puisé dans l'architecture de la Rome antique l'idée de ces coursières murales qui devaient conditionner la structure gothique. Les Orientaux propageaient la formule de la gaine depuis le haut Moyen Âge. Mais il est possible que les Français l'aient retrouvée spontanément sous l'aiguillon du besoin, sans nulle aide extérieure et par le jeu de leur seule réflexion. Certains archéologues, minimisant les facultés créatrices de nos ancêtres médiévaux, ont à mon

"I. Vallery-Radot: Quelques donjons de Philippe Auguste, dans le «Bull. de la Soc, nat, des antiquaires de France», 1964, pp. 156-158.

${ }^{42} \mathrm{~L}$. BRoche: L'ancien palais des rois à Laon, dans le «Bull. de la Soc, académique de Laon», t. XXXI, 1900-1904, p. 195.

43 Lefèvre-Pontalis et Lauer: Le château de Coucy, op, cit., pp. 87 et 92-95. 


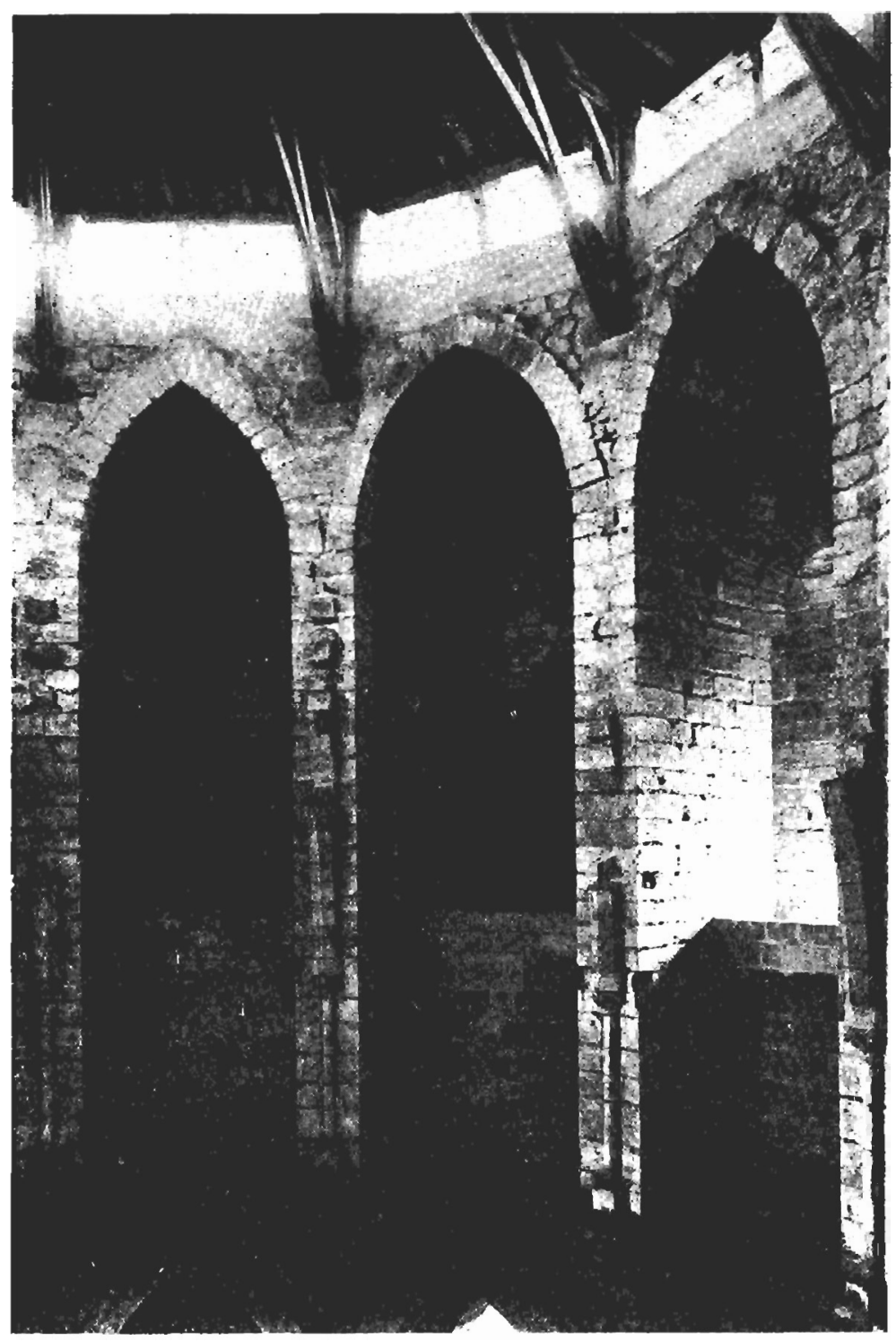

Fig. 10.-Coucy. Donion, coursière de la salle haute.

(Coll. E. Lefèvre-Pontalis). 
sens exagéré l'importance des apports levantins dans l'évolution de notre architecture militaire du $\mathrm{XI}^{\mathrm{c}}$ siècle au début du XIII ${ }^{c}{ }^{44}$

Quoi qu'il en soit, la gaine fit à ma connaissance ses premières apparitions dans l'empire byzantin. Au VI ${ }^{c}$ siècle Justinien ordonna de surhausser les remparts de deux places voisines de la frontière persane: Dara dans le Kurdistan, sur les confins irako-turco-syriens, et Theodosiopolis que nous appelons Erzerum. À la faveur de cette opération l'on coiffa le chemin de ronde primitif d'une voûte sur laquelle on assit un nouveau chemin de ronde. On créa de la sorte au sommet des courtines deux niveaux de tir superposés, constitués par un couloir couvert, armé de meurtrières, et au dessus par une coursière crénelée à l'air libre. ${ }^{45}$ Les musulmans s'emparèrent du thème, mais sans lui donner beaucoup d'extension. Erigée au VIII ${ }^{\mathrm{e}}$ siècle, l'enceinte du palais abbasside d'Ukhaidir en Irak contient une galerie voûtée en berceau, ménagée au coeur de la muraille, à courte distance du chemin de ronde. Large de près de deux mètres et haute de cinq, elle desservait les étages supérieurs des tours. On la dota de fenêtres exiguës vers la cour et d'archères vers le dehors. ${ }^{46}$ Il en existe des répliques de moindre gabarit dans les remparts des ville ${ }^{47}$ et citadelle ${ }^{48}$ du Caire, respectivement bâties à la fin des $\mathrm{XI}^{\circ}$ et $\mathrm{XII}^{c}$ siècles.

Les Latins de Terre Sainte ne laissèrent pas non plus de rééditer la gaine çà et là, mais assez tardivement, semble-t-il. Actuellement sis en Turquie, entre Antioche et Alexandrette, le château de Baghrâs se répartit sur deux niveaux. Le corps principal, juché sur un socle rocheux, en est précédé d'une ligne de défenses occupant le palier inférieur. Le plus important de ces ouvrages, un bastion construit au XII ${ }^{\mathrm{e}}$ ou XIII ${ }^{\mathrm{e}}$ siècle et s'adossant au rocher, contient une large galerie qui portait une plateforme. Voûtée en berceau, cette galerie est armée de meurtrières. ${ }^{49}$

"Cf. P. Héliot: Evolution du donjon, op. cit., p. 190, et Le Château-Gaillard et les forteresses des XII' et XIII' s. en Europe occidentale, dans «Château Gaillard», t. I, 1962, pp. 63-67.

is S. ToY: A bistory of fortification, op. cit., pp. 56-57. Bâtie à la même époque à l'entrée des Dardanelles, la forteresse d'Elaeus offrait des dispositions analogues (ibid., 61).

${ }^{46}$ K. A. C. CReswell: Early Muslim arcbilecture, Oxford 1932-1940, t. II, p. 55, et Fortification in Islam before A.D. 1250, dans les «Proceedings of the British Academy», 1952, p. 109; Eydoux: Châteaux fanlastiques, op. cit., t. III, pp. 252 et 258.

"CReswell: Fortification, cit., p. 116.

${ }^{4}$ K. A. C. CReswell: Archaealogical researches at the citadel of Cairo, dans le «Bull. de l'Institut français d'archéol. orientale», t. XXIII, 1924, p. 103 suiv., et Forlification, cit., fig. 15.

${ }_{43}$ W. MǗLLER-WIENER: Burgen der Kreuzritter, München-Berlin 1966, pp. 50, 51 et 100 , pl. 28 et 30 . 


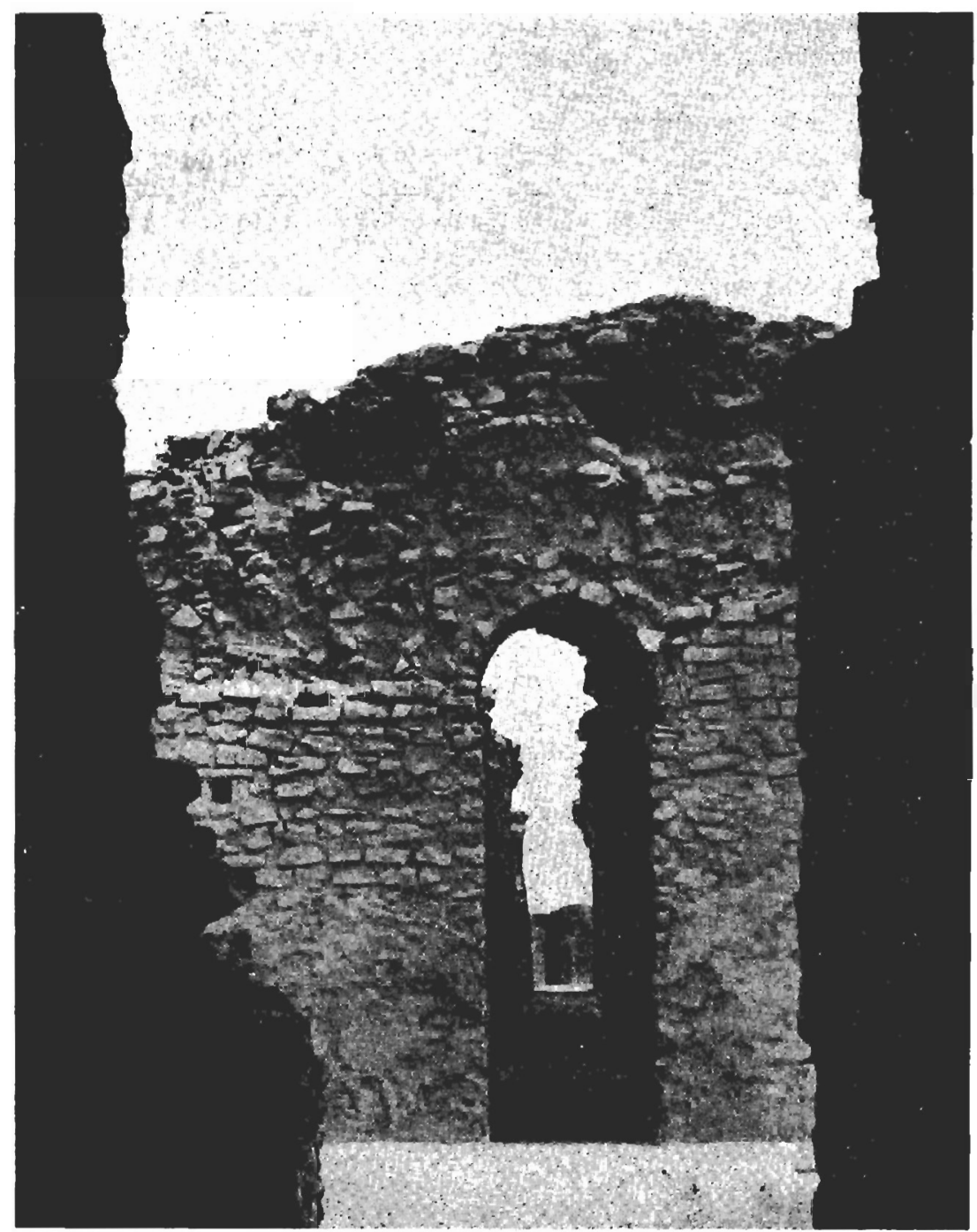

FIG. 11.-Ukhaidir. Palais, ruines de la gaine de l'enceinte. (Coll. H.-P. Eydoux). 
Ne quittons pas encore l'ancienne «prircée» d'Antioche, où le donjon du château syrien de Margat (Markab) fut renouvelé par les Hospitaliers, sans doute peu après 1186. Le mur épais qui enveloppe cette tour offre deux niveaux de tir, car la terrasse à ciel ouvert y couvre une gaine circulaire, également gratifiée d'archères. ${ }^{50}$ Sous une date assez voisine de 1200 les moines-guerriers du même ordre renforcèrent leur fameuse forteresse du Crac des Chevaliers (Qalaat el Hosn) en Syrie. Ils commencèrent par empâter les fronts ouest et sud de l'enceinte intérieure dans un énorme talus de maçonnerie, dans lequel ils logèrent une large galerie voûtée en berceau, longue de $200 \mathrm{~m}$. sur sa branche principale et chichement éclairée par d'étroites meurtrières. Remontant le rempart au dessus de ce glacis, ils réservèrent dans son épaisseur deux couloirs superposés, voûtes d'arêtes cette fois, mais encore pourvus de meurtrières. ${ }^{51}$ Ils créèrent de la sorte quatre niveaux de tir, y compris le chemin de ronde à l'air libre.

Passons maintenant dans la partie de l'ex-royaume de Jérusalem incluse de nos jours en territoire d'Israël. En 1218 les Templiers érigèrent le Chastel-Pèlerin (Athlit) sur une péninsule qu'ils barrèrent à sa naissance au moyen de deux murailles parallèles. Evidant le rempart extérieur, une gaine voûtée desservait des casemates dotées d'archères, tout en reliant entre elles les salles du premier étage des tours, tandis qu'un couloir analogue et que des escaliers également aménagés dars la courtine assuraient les communications entre les deux grosses tours du rempart intérieur. ${ }^{52}$ A Césarée enfin, dont saint Louis fit renouveler l'enceinte urbaine en 1251, on assit comme au Crac les courtines et les tours sur un haut talus de maçonnerie, qui contenait une galerie de contremine, voûtée en quart de cercle et gratifiée de maigres ajours: simples rainures percées au sommet du glacis et fort impropres au tir en raison de leur situation. ${ }^{53}$

Le donjon-palais de Lucera en Apulie dérivé sans doute des donjons normands de l'Italie méridionale, tels qu'Adrano et Paterno en Sicile, dont on développa cependant la formule en y incorporant celle, plus complexe, du castellum antique, transmise selon toute vraisemblance par l'intermédiaire de forteresses byzantines ou sarrasines. L'empereur Frédéric II, qui venait de passer une année en Orient, le mit en chantier vers 1235. Quatre petits corps de logis enchâssant une étroite cour carrée

5. G. Rey: Étude sur les monum. de l'arcbil. militaire des Croisés en Syrie el dans l'alle de Chypre, Paris 1871 , p. 30.

${ }_{51}$ P. Deschamps: Les cháleaux des Croisés en Terre Sainle, Paris 1934-1939, t. I, pp. 183, 184, 188, 195, 196, 204 et 205.

${ }_{52}^{2}$ C. N. Jouns: Excavalions al Pilgrims' Caslle, 'Allit, dans «The Quatterly of the department of antiquities in Palestine», t. III, 1933, PP. 152-155; R. FEDDEN et J. Thompson: Crusader caslles, Londres 1957, p. 94.

${ }_{53}$ Rey, op. cit., p. 224. 
composaient l'édifice. Un talus de maçonnerie, dissimulant le rez-dechaussée, abritait par surcroît une large galerie périphérique, voûtée en quart de cercle et à laquelle des archères donnaient un peu de jour. Ce couloir en surmontait un autre, simplement plafonné et apparemment voué à l'écoute. ${ }^{54}$ Daté de 1247 , le donjon de Termoli en Capitanate est aussi l'oeuvre du dernier des Staufen. Il évoque le précédent dont il

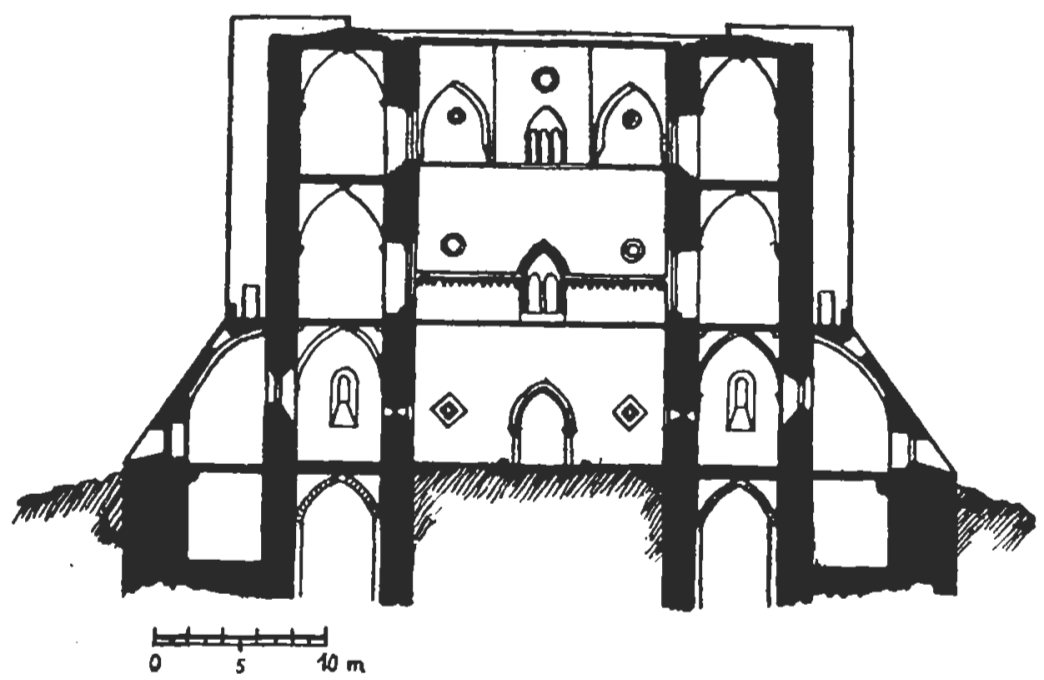

FIg. 12-Lucera. Donion, coupe reconstituée par W. Körte.

constitue une réduction. C'est une tour de plan carré, plantée sur un haut piédestal en maçonnerie, qui affecte la forme d'un tronc de pyramide à quatre faces. Une gaine voûtée en berceau, large d'environ $2,50 \mathrm{~m}$. et gratifiée de meurtrières, contourne le socle près de son sommet, sous la plateforme d'un chemin de ronde à ciel ouvert comme à Lucera. ${ }^{55} \mathrm{Je}$ rattacherais volontiers les gaines de ces deux édifices à des modèles

“ A. Haseloff: Die Bauten der Hohenstauten in Unteritalien, Leipzig 1920, t. I, pp. 189.233 et pl. 9 suiv. de l'album; H. HAHN: Hobenstautenburgen in Süditalien, Ingelheim 1961, pp. 36-39, 76 et 77; W. KRönIG: Staulische Baukunst in Unteritalien, dans les «Beiträge zur Kunst des Mittelalters», I. I, 1948, pp. 29-30. Je n'ai pas eu en mains l'article de W. KörTE: Das Kastell Kaiser Friedrichs II in Lucera, dans 25 Jahrc Kaiser Wilhelm Gesellschaft zur Förderung der Wissenschalten, Berlin 1937, 1. III.

is Hasfi.off, op. cit., 1. I, p. 357 suiv, et pl. 34 suiv. de l'album; $H_{\Lambda H N}$, op. cit., pp. 11 er 64. 
orientaux. Plus volumineux et plus saillants que leurs congénères des forteresses contemporaines de l'Europe, les hauts talus maçonnés qui les contiennent corroborent mon hypothèse.

L'explication vaut-elle pour les gaines de France, d'Angleterre et d'Espagne? Il est probable qu'à l'instar des coursières d'églises, la gaine découlait des niches profondément encastrées dans la masse de certains remparts antiques, que les Grecs et les Levantins avaient légué aux Romains: niches voûtées et reliées entre elles par des passages latéraux qui assuraient une circulation continue. ${ }^{56}$ Après tout mes compatriotes auraient pu s'inspirer des galeries d'une vieille forteresse d'Occident, encore existante en leur temps: telle que l'enceinte dont l'empereur Aurélien avait enveloppé la Ville Éternelle. Ici un chemin de ronde supplémentaire, réservé dans la moitié supérieure des murailles, s'ouvrait à travers de larges arcades vers l'intérieur de la cité. Cette filiation n'est pas moins plausible que la conjecture d'un emprunt direct aux architectures byzantine et musulmane qui, elles aussi, avaient recueilli, puis interprété le thème initial, diffusé dans les différentes provinces de l'empire des césars. Archaïsme choquant -me dira-t-on-, recours peu vraisemblable aux fossiles d'une civilisation depuis longtemps éteinte; mais aussi à une architecture glorieuse, restée prestigieuse encore aux $\mathrm{XI}^{\mathrm{e}}$ et $\mathrm{XII}^{\mathrm{c}}$ siècles puisque les maîtres d'oeuvre romans en tirèrent leurs thèmes et leurs procédés de rénovation de la bâtisse. Fort douteuse au Mont-SaintMichel et à Loches en raison d'une date de construction relativement reculée -contemporaine de la première croisade ou légèrement antérieure-, l'intervention de l'Orient ne me paraît probable qu'à Lucera et Termoli. Ailleurs elle est incertaine, même à Saint-Pons-de-Thomières et à Villefranche-de-Conflent où l'on adopta la solution de Dara et d'Ukhaidir, qu'allaient reprendre aussi les Francs de Syrie et de Palestine.

Quoi qu'il en soit, ce problème généalogique n'a somme toute qu'une importance secondaire. Tantôt simple couloir de circulation reliant à couvert des ouvrages éloignés l'un de l'autre, tantôt galerie desservant un niveau de tir supplémentaire, tantôt enfin poste d'écoute et point de départ pour des contremines, la gaine ne semble pas avoir obtenu grand succès auprès des ingénieurs militaires du Moyen Âge. A l'abri des flèches et des carreaux d'arbalète, mais non des gros projectiles, elle affaiblissait la capacité de résistance des murs au bombardement. Telle est

s6 L. Crema: L'archilettura romana, Turin 1959, p. 558 et fig. $738 ; G, T, R_{1}-$ voIRA: Archilettura romana: costruzione $e$ statica nell'età imperiale, Milan 1921, pp. 241-242, et Le origini della architeltura lombarda e delle sue principali derivazioni nei paesi d'oltr'Alpe, Rome 1901-1907, t. II, p. 107; G. Lugli: La tecnica edilizio romana, Rome 1957, t. II, pl. 178. Cf. HÉliot: La calbédrale de Cefalu, op. cit., p. 9. 
sans doute la raison principale de sa maigre popularité. Je ne saurais certes prétendre avoir détecté la totalité de celles qui subsistent, même en France, ne serait-ce qu'à l'état de vestiges. Je suis persuadé qu'on en trouvera d'autres, mais je doute qu'il y en ait eu jadis beaucoup en mon pays. Les archéologues s'en étant fort peu souciés jusqu'ici, je souhaite qu'ils prennent désormais la peine de décrire, chaque fois que l'occasion s'en présentera, un organe de fortification fort intéressant et pourtant injustement négligé. ${ }^{77}$

${ }^{57}$ J'ai le plaisir de remercier jci de fort aimables collaborateurs: M. Henri-Paul Eydoux, qui m'a communiqué plusieurs photographies suggestives; M. Elie Auriault, qui m'a envoyé ses excellents plans du château du Coudray-Salbart; enfin, M. Cathcart King, qui m'a permis de publier son plan du donjon de Flint. 